\title{
A reducing redox environment promotes C2C12 myogenesis: Implications for regeneration in aged muscle
}

\author{
Jason M. Hansen ${ }^{a}$, Markus Klass ${ }^{a}$, Craig Harris ${ }^{b}$, Marie Csete ${ }^{a, *}$ \\ ${ }^{a}$ Department of Anesthesiology, School of Medicine, Emory University, 1462 Clifton Road NE, Suite 420, Atlanta, GA 30322, USA \\ ${ }^{\mathrm{b}}$ Toxicology Program, Department of Environmental Health Sciences, School of Public Health, University of Michigan, Ann Arbor, MI 48109, USA
}

Received 7 December 2005; revised 13 November 2006; accepted 29 November 2006

\begin{abstract}
Intracellular redox potential of skeletal muscle becomes progressively more oxidized with aging, negatively impacting regenerative ability. We examined the effects of oxidizing redox potential on terminal differentiation of cultured C2C12 myoblasts. Redox potentials were manipulated by changing the culture $\mathrm{O}_{2}$ environment, by free radical scavenging, or addition of $\mathrm{H}_{2} \mathrm{O}_{2}$. Intracellular reactive oxygen species (ROS) production was higher in $20 \%$ environmental $\mathrm{O}_{2}$ and in this condition, redox potential became progressively oxidized compared to cultures in $6 \% \mathrm{O}_{2}$. Treatment with a ROS trapping agent (phenyl- $\mathrm{N}$-tert-butylnitrone, $\mathrm{PBN}$ ) caused reducing redox potentials and enhanced $\mathrm{C} 2 \mathrm{C} 12$ differentiation, while addition of 25 micromolar $\mathrm{H}_{2} \mathrm{O}_{2}$ to cells in $20 \% \mathrm{O}_{2}$ dramatically slowed differentiation. Under these most oxidative conditions, quantitative PCR showed a significant decrease in myogenic basic helix-loop-helix transcription factor expression compared to cultures treated with $\mathrm{PBN}$ or grown in $6 \% \mathrm{O}_{2}$. Thus, oxidative intracellular environments impair myoblast differentiation, while reducing environments favor myogenesis.
\end{abstract}

(C) 2006 International Federation for Cell Biology. Published by Elsevier Ltd. All rights reserved.

Keywords: C2C12 myoblast; Muscle aging; Myoblast; Myogenin; Redox potential

\section{Introduction}

The resident stem cell population of adult skeletal muscle, the satellite cell, is the major source for replacing muscle lost as a consequence of overuse, disuse, or degenerative processes. Muscle repair is usually adequate through middle age, but by age 80 , humans have lost about $40 \%$ of their muscle mass and more than $50 \%$ of their ability to generate power (Faulkner et al., 1995). Age-related muscle mass and functional loss is correlated generally with loss of reducing potential with age (Hazelton and Lang, 1985; Noy et al., 1985), reflected in increases in glutathione/glutathione disulfide (GSH/GSSG) ratio in tissues and plasma. GSH/GSSG is a redox couple of particular importance because, as the single largest cellular source of reducing equivalents (up to 90\%)

\footnotetext{
* Corresponding author. Tel.: +1 404712 2588; fax: +1 4047122585 .

E-mail address: marie.csete@emoryhealthcare.org (M. Csete).
}

(Cotgreave and Gerdes, 1998), GSH serves as a reliable indicator of intracellular redox status (Schafer and Buettner, 2001). In parallel with decreased ratios of cytosolic GSH to GSSG in aged muscle, markers of oxidative damage increase in all cellular compartments. Aged human muscle accumulates increased levels of 8-hydroxy-2-deoxyguanosine, protein carbonyls and malondialdehyde, markers of oxidative damage to DNA, proteins and lipids, respectively (Mecocci et al., 1999; Pansarasa et al., 2000). In summary, intracellular redox status in aged skeletal muscle shifts to a more oxidizing milieu, permitting local persistence of reactive oxygen species (ROS) (Hamilton et al., 2001) and progressive oxidative damage. Despite the central role of an oxidized environment in muscle aging, the differentiation patterns of myoblasts as a function of oxidative stress in the microenvironment have not been well described.

Redox status affects virtually all cellular processes including DNA synthesis, transcriptional activation, enzyme kinetics, 
protein folding (Sen and Packer, 1996; Cotgreave and Gerdes, 1998) and trafficking (Pfau et al., 2004). Differentiation processes, then, are inevitably impacted by redox potential changes. Intracellular redox status is dependent on the abundance of reduced partners of redox couples, particularly GSH. GSH is used directly in many of the biochemical reactions that mediate survival responses to oxidative stress. For example, under conditions of moderate oxidative stress a thiol group in the transcription factor NF kappa-B undergoes a two-stage modification by $\mathrm{H}_{2} \mathrm{O}_{2}$ and a reaction requiring GSH. The resulting post-translational modification ( $S$-glutathionylation) causes impaired NF kappa-B DNA binding (Pineda-Molina et al., 2001). These and other studies point to $\mathrm{H}_{2} \mathrm{O}_{2}$ as a ubiquitous second messenger (Reynaert et al., 2006) during physiologic and pathologic conditions of oxidant stress.

In this study we focus on redox-regulated expression of the myogenic basic helix-loop-helix transcription factors (muscle regulatory factors; MRFs) that are the core regulators of skeletal muscle differentiation. Four MRFs (myf5, mrf4, MyoD, myogenin) constitute this family. Except for myf5 (Beauchamp et al., 2000) undifferentiated satellite cells do not express these factors. Activation of satellite cells for muscle regeneration is marked by expression of MRFs in a precisely coordinated temporal pattern (Yun and Wold, 1996). MyoD and myf5 are expressed early in muscle development and differentiation, and have overlapping functions (Rudnicki et al., 1992). Mrf4 is expressed transiently early in development and is also involved in terminal differentiation. Myogenin plays its role later in terminal muscle differentiation (reviewed in Berkes and Tapscott, 2005).

The $\mathrm{C} 2 \mathrm{C} 12$ cell line is a standard model for the study of muscle differentiation (Yaffe and Saxel, 1977). These mononuclear myoblasts differentiate into fused, multinucleated myotubes over the course of a few days upon mitogen withdrawal, recapitulating developmental and regenerative myogenesis. Because intracellular redox status is increasingly recognized as an important regulator of transcriptional activation, our objective was to characterize $\mathrm{C} 2 \mathrm{C} 12$ myogenesis under varied oxidizing and reducing conditions. These studies show that optimal skeletal muscle differentiation is promoted under reducing intracellular redox potentials and inhibited under more oxidizing redox potentials. Understanding redox sensitivity in muscle differentiation is a potentially powerful approach for identifying new pathways and pharmacologic tools to enhance muscle regeneration, especially in the context of aging.

\section{Materials and methods}

\subsection{Materials}

C2C12 cells were from American Type Cell Collection (Manassas, VA, USA), and all sera from HyClone (Logan, UT, USA). Mf20 antibody, developed by Donald A. Fischman, was from the Developmental Studies Hybridoma Bank developed under the auspices of the NICHD and maintained by the University of Iowa Department of Biological Sciences, Iowa City, IA, USA. 5-(and-6)-carboxy-2 $2^{\prime}, 7^{\prime}$ - Dichlorodihydrofluorescein diacetate (DCF) and Alexa 568 secondary antibodies were from Molecular Probes (Eugene,
OR, USA). All HPLC columns, equipment and software were from Waters (Milford, MA, USA). Diethylenetriamene pentaacetate (DTPA), HEPES buffer, PBN, and methanesulfonic acid (MSA) were purchased from Sigma (St. Louis, MO, USA). Vectashield with 4'-6-diamidino-2-phenylindole (DAPI) was purchased from Vector Labs (Burlingame, CA, USA). Dulbecco's Modified Eagle's Medium (DMEM), glutamine and penicillin-streptomycin were from Life Technologies (Grand Island, NY, USA). Modular incubators for lowered $\mathrm{O}_{2}$ culturing were from Billups-Rothenburg (Del Mar, CA, USA) and cell manipulations were handled in a customized, gas-controlled hood (Coy Labs, Grass Lake, MI, USA).

\subsection{Animals}

Young (6-7 months old) and aged (31-32 months old) CBA mice were purchased from the National Institute of Aging (NIA) breeding colony. Housing and handling of mice followed protocols approved by institutional IUCUC, and NIH guidelines.

\subsection{Cell culture}

C2C12 myoblasts were grown until confluence in growth medium $(15 \%$ fetal bovine serum in DMEM containing $2 \mathrm{mM}$ glutamine and antibiotics) then switched to differentiation medium (2\% horse serum in DMEM containing $2 \mathrm{mM}$ glutamine and antibiotics). The addition of differentiation medium is defined as the zero time-point in all experimental protocols. For culture in $6 \% \mathrm{O}_{2}$, cells were placed into modular incubators (Billups-Rothenberg, DelMar CA, USA) after equilibration in a gas-controlled environment. $\mathrm{CO}_{2}$ was maintained at $5 \%$ for all experiments. Cultures maintained at $20 \% \mathrm{O}_{2}$ were treated with either $1 \mathrm{mM}$ PBN or $25 \mu \mathrm{M} \mathrm{H}_{2} \mathrm{O}_{2}$. All differentiation experiments were carried out for $72 \mathrm{~h}$.

\subsection{DCF detection of ROS in cultured myoblasts}

DCF was used to determine the production of reactive oxygen species, specifically the production of $\mathrm{H}_{2} \mathrm{O}_{2}$ (LeBel et al., 1992), using a modification of published protocols (Wang and Joseph, 1999). DCF $(100 \mu \mathrm{M})$ was added to $\mathrm{C} 2 \mathrm{C} 12$ cells in serum-free medium for $45 \mathrm{~min}$. After washes with PBS, the cells were incubated in serum-containing medium at either $6 \%$ or $20 \% \mathrm{O}_{2}$ for $24 \mathrm{~h}$. DCF fluorescence was measured using a Molecular Devices Gemini XS fluorometer (Sunnyvale, CA, USA) at $488 \mathrm{~nm}$ (excitation) and $518 \mathrm{~nm}$ (emission). Data gathered from a total of 46-48 wells per condition are presented as relative fluorescence units (RFU)/well \pm SEM, and differences between conditions were analyzed using Student's standardized $t$-tests.

\subsection{High-pressure liquid chromatography (HPLC) measurement of glutathione (GSH) and glutathione disulfide (GSSG) concentrations}

At $0,24,48$, or $72 \mathrm{~h}$ of differentiation, $\mathrm{C} 2 \mathrm{C} 12$ cells were collected in $200 \mathrm{mM}$ methane sulfonic acid (MSA), snap-frozen in liquid $\mathrm{N}_{2}$, and stored at $-70{ }^{\circ} \mathrm{C}$ until HPLC derivatization and analysis. Similarly, hamstring muscle (including biceps memoirs, semitendinosus, semimembranosus) from young and aged CBA mice were dissected in PBS, frozen with liquid $\mathrm{N}_{2}$, pulverized, placed in $200 \mathrm{mM}$ MSA and stored as described above until analysis. Glutathione concentration was determined using published protocols (Newton and Fahey, 1985; Harris, 1993). Sodium methanesulfonate (4 M) was added to homogenized samples to precipitate protein, followed by centrifugation at $13,900 \mathrm{rpm}$ (about $12 \times \mathrm{g}$ ) for $5 \mathrm{~min}$ at $5{ }^{\circ} \mathrm{C}$. The resulting supernatants were split into two equal portions for GSH and GSSG analyses and GSH samples placed into $5 \mathrm{mM}$ diethylenetriaminepentaacetic acid (DTPA) in $1 \mathrm{M}$ HEPES ( $\mathrm{pH}$ 8.5). Derivitization was carried out by the addition of $0.2 \mathrm{mM}$ monobromobimane (thiolyte), followed by $20 \mathrm{~min}$ incubation in the dark at room temperature. Derivitization was terminated by the addition of $400 \mathrm{mM}$ MSA, then the samples were snap-frozen in liquid $\mathrm{N}_{2}$, and stored at $-70^{\circ} \mathrm{C}$.

HPLC analyses were carried out using a Waters NovaPak C 4-mm RadialPak cartridge fitted with a NovaPak Guard-Pak guard pre-column. Samples 
were eluted using an isocratic mobile phase consisting of $14.2 \%$ methanol $(\mathrm{v} / \mathrm{v})$ and $2.5 \%$ glacial acetic acid $(\mathrm{v} / \mathrm{v})$ at a flow rate of $1.0 \mathrm{ml} / \mathrm{min}$. Following elution of the GSH peak, the column was washed with $90 \%$ methanol (v/v) and $2.5 \%$ glacial acetic acid (v/v) for $15 \mathrm{~min}$. Detection of GSH-bimane was accomplished using a Waters Model 470 scanning fluorescence detector (excitation $360 \mathrm{~nm}$; emission $455 \mathrm{~nm}$ ) followed by analysis and quantitation using a Waters Model 746 data module. Authentic standards were prepared and used to identify and quantify each peak of interest. This HPLC method accurately detects GSH and cysteine levels down to 10 pmol per $200 \mathrm{ml}$ injection.

For GSSG analyses, samples were prepared as for GSH, except that GSSG supernatants were placed into $5 \mathrm{mM}$ DPTA and $3.5 \mathrm{mM}$ dithiothreitol (DTT) in $1 \mathrm{M}$ HEPES ( $\mathrm{pH} 8.5$ ). Samples were incubated at $37^{\circ} \mathrm{C}$ for $30 \mathrm{~min}$ prior to derivatization with monobromobimane to reduce GSSG to GSH. Derivatization was then carried out by adding monobromobimane $(2 \mathrm{mM})$ in acetonitrile for $20 \mathrm{~min}$ and terminated by addition of $400 \mathrm{mM}$ MSA. Samples were stored at $-70{ }^{\circ} \mathrm{C}$ until HPLC analysis. Glutathione disulfide concentrations were determined by quantitation of the GSH peak, subtraction of prior GSH measurement above, and division by 2. Final concentrations were normalized to protein content (Bradford, 1976). Cysteine (Cys) and cystine (CysSS) detection was performed similarly, with cysteine standards used to quantify the sample HPLC peaks.

GSH and GSSG concentration differences in mouse muscle were analyzed by $t$-tests (SigmaStat 2.0, Jandel Scientific). Cell culture concentration differences were analyzed by one-way ANOVA (Tukey's post hoc test). Concentrations were considered significantly different if $p<0.05$.

\subsection{Calculation of intracellular redox potential}

The Nernst equation was adapted to calculate intracellular redox status using GSH and GSSG concentrations (Sen and Packer, 1996; Kirlin et al., 1999) as follows:

$E=E_{\mathrm{o}}-(2.303 R T / n F) \log \left([\mathrm{GSH}]^{2} /[\mathrm{GSSG}]\right)$

where $E_{\mathrm{o}}$ is the standard potential of GSH $(-0.24 \mathrm{mV}), R$ is the gas constant $(8.31 \mathrm{~J} / \mathrm{deg} \mathrm{mol}), T$ is the absolute temperature $(298 \mathrm{~K}), n$ is the number of electrons transferred (two), and $F$ is the Faraday constant $(96,406 \mathrm{~J} / \mathrm{V})$. Redox potentials are presented as mean millivolts $(\mathrm{mV}) \pm \mathrm{SEM}$, and differences between conditions were analyzed using one-way ANOVA.

\subsection{Immunocytochemistry}

Anti-myosin heavy chain immunoreactivity was used as one criterion of terminal muscle differentiation. Cultures were fixed in methanol:acetone (1:1), dried overnight, and then rehydrated with PBS. Cells were blocked using $10 \%$ donkey serum in PBS for $30 \mathrm{~min}$, then incubated with Mf20 mouse monoclonal antibody (1:5 dilution in PBS) against myosin heavy chain (MHC) for $2 \mathrm{~h}$ at room temperature, followed by three PBS washes. Secondary goat anti-mouse Alexa 568 antibody was incubated for $45 \mathrm{~min}$. After washes, cells were mounted in Vectashield containing 4',6-diamidino-2-phenylindole (DAPI), from Vector Labs, Burlingame CA, USA. Differentiation was quantified using fluorescence microscopy. $\mathrm{C} 2 \mathrm{C} 12$ cells were counted as differentiated if they were MHC-positive and incorporated into a myotube with $>3$ nuclei (Kim et al., 1998). The percentage of differentiated cells is presented as mean $\pm \mathrm{SEM}$, and differences between groups were analyzed using oneway ANOVA.

\subsection{Western blotting}

Cells were collected in protein extraction reagent (Pierce, Rockford IL, USA) with phosphatase and protease inhibitors, then stored at $-80{ }^{\circ} \mathrm{C}$ until assayed. Protein concentration was determined using the Bradford method (Bradford, 1976). Sixty micrograms of total protein was loaded per well on $12 \%$ agarose gels (Bio-Rad, Hercules CA, USA). Proteins were transferred to nitrocellulose membranes (Amersham, Piscataway NJ, USA), then the membranes blocked with TBS $+5 \%$ nonfat milk and $0.1 \%$ Tween- 20 for $2 \mathrm{~h}$ at room temperature. All antibodies: rabbit polyclonal $\alpha$-activated caspase-3, mouse monoclonal $\alpha$-p38 mitogen-activated protein kinase (MAPK), and $\alpha$ phospho-p38 MAPK (Cell Signaling Technology, Boston MA, USA) were incubated overnight at $4{ }^{\circ} \mathrm{C}$ at a dilution of $1: 1000$. After TBS-T washes, membranes were incubated with the appropriate secondary antibodies: Goat $\alpha$-rabbit IgG conjugated to horse radish peroxidase (1:3000) for activated caspase- 3 or goat $\alpha$-mouse IgG conjugated to horse radish peroxidase (1:3000) for MAPKs in 5\% nonfat milk for $1 \mathrm{~h}$ at room temperature, then washed again. The reaction was developed using enhanced chemiluminescence (ECL, Amersham, Piscataway, NJ, USA).

\subsection{Quantitation of bHLH gene expression}

Cultures were washed with PBS, and total RNA isolated using RNeasy (Qiagen, Valencia CA, USA). Reverse transcription of RNA was performed with M-MLV RT using $1 \mu \mathrm{g}$ RNA, $40 \mathrm{mM}$ dithiothreitol, $0.5 \mathrm{mM}$ dNTPs, 10 U RNAase inhibitor, and $200 \mathrm{ng}$ random primers (all reagents from Promega, Madison, WI, USA). The reaction was incubated for $1 \mathrm{~h}$ at $37^{\circ} \mathrm{C}$.

Primers for myf-5, MyoD, MRF-4 and myogenin were from published protocols (Cornelison and Wold, 1997). $\beta$-Actin PCR was used as an internal control (forward primer: 5'-TCACCCACACTGTGCCCATGTACGA-3'; reverse primer $5^{\prime}$-CCTACGGTGTTCTAAGGTATGGGT-3').

Real-time PCR was performed using a LightCycler and the LightCycler FastStart DNA Master SYBR Green I kit (Roche, Indianapolis IN, USA). Reactions using $50 \mathrm{ng}$ of cDNA from each condition included a preincubation $\left(95^{\circ} \mathrm{C}\right.$ for $5 \mathrm{~min}$ ), 45 amplification cycles, and melting curve analysis for verification of specific product. Products were also run on $2 \%$ agarose gels to verify size. The myf- 5 amplification cycle used annealing at $57^{\circ} \mathrm{C}$ for $7 \mathrm{~s}$ and elongation at $72{ }^{\circ} \mathrm{C}$ for $14 \mathrm{~s}$. The MyoD amplification cycle used annealing at $64{ }^{\circ} \mathrm{C}$ for $7 \mathrm{~s}$ and elongation at $72^{\circ} \mathrm{C}$ for $16 \mathrm{~s}$. The MRF- 4 amplification cycle used annealing at $57^{\circ} \mathrm{C}$ for $7 \mathrm{~s}$ and elongation at $72{ }^{\circ} \mathrm{C}$ for $14 \mathrm{~s}$. The myogenin amplification cycle used annealing at $59^{\circ} \mathrm{C}$ for $7 \mathrm{~s}$ and elongation at $72{ }^{\circ} \mathrm{C}$ for $14 \mathrm{~s}$. The $\beta$-actin amplification cycle used annealing at $60^{\circ} \mathrm{C}$ for $7 \mathrm{~s}$ and elongation at $72{ }^{\circ} \mathrm{C}$ for $21 \mathrm{~s}$.

\section{Results}

\subsection{Young vs. aged mouse muscle}

Glutathione concentrations in young mouse muscle (41.4 pmol GSH/ $\mu \mathrm{g}$ protein \pm 4.49 ) were higher but not significantly so $(p=0.054)$ than GSH concentrations in old mouse muscle (33.4 pmol GSH/ $\mu$ g protein \pm 5.01 ) (Fig. 1). Absolute GSSG concentrations were not statistically different as a consequence of age. However, GSH:GSSG ratios, which define the overall redox potentials, did differ significantly $(p<0.001)$. In young mouse muscle, GSH:GSSG ratios were $25.1 \pm 5.28$ but significantly more oxidized at $4.7 \pm$ 0.73 in old muscle.

To further describe the oxidative state of muscle with aging, the cysteine:cystine ratio was also measured. GSH prevents cysteine oxidation but age-related changes in the Cys/CysSS ratio have not been reported in muscle. Our data indicate that the Cys/CysSS ratio is more oxidized with aging in murine muscle, as has recently been reported for human plasma (Jones et al., 2002).

\subsection{Reactive oxygen species and redox potentials in differentiating C2C12 myoblasts}

After only $24 \mathrm{~h}$ in $6 \% \mathrm{O}_{2}, \mathrm{C} 2 \mathrm{C} 12$ cells contained significantly less ROS, as assessed by DCF fluorescence, compared 
A

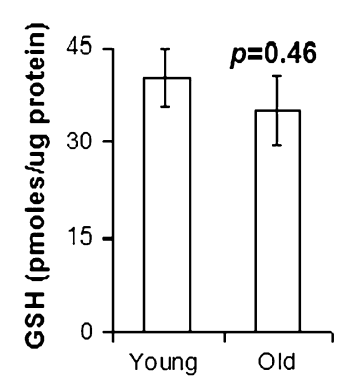

D

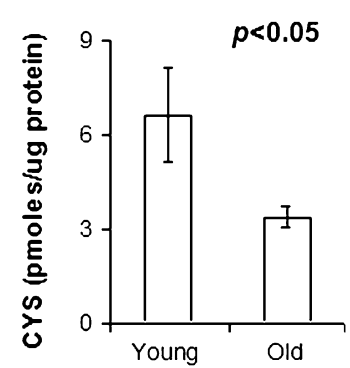

B

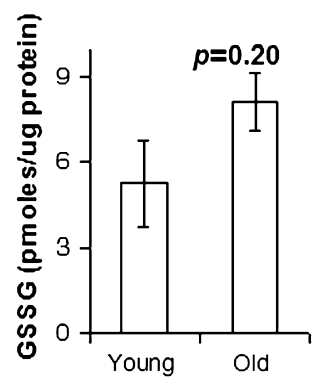

E

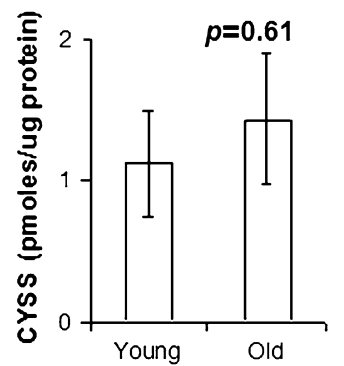

C

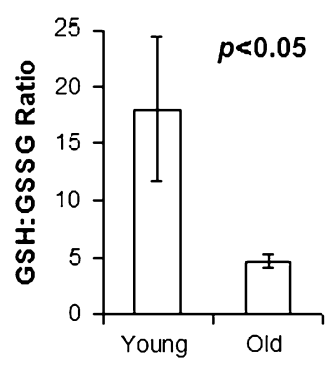

$\mathbf{F}$

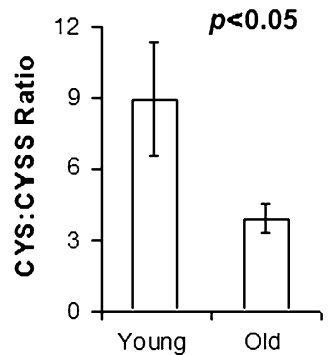

Fig. 1. GSH:GSSG and cysteine:cystine ratios in young vs. aged murine hamstring. GSH concentration was not significantly different in young vs. aged muscle (A) and GSSG was also similar in the two groups (B). However, reducing potential, indicated by GSH:GSSG ratio was significantly lower in old muscle (C). Cysteine was less abundant in aged muscle (D), cystine levels were similar (E), and the ratio of cysteine:cystine was significantly lower in aged muscle (F). These data support significant loss of reducing potential in aged vs. young skeletal muscle.

to traditional $20 \% \mathrm{O}_{2}$ culture conditions: $5.79 \pm 0.14$ vs. $7.85 \pm 0.31 \mathrm{RFU} /$ well $(n=48, p<0.001)$.

\subsection{Redox potential of differentiating myoblasts as a function of oxygen, peroxide, or free radical scavenging}

The redox potential patterns of differentiating $\mathrm{C} 2 \mathrm{C} 12$ cells are shown in Fig. 2. In general, myoblasts cultured in $20 \% \mathrm{O}_{2}$ showed progressively oxidized redox potentials over $72 \mathrm{~h}$, whereas myoblasts cultured in $6 \% \mathrm{O}_{2}$ maintained quite constant redox potential. Interestingly, the addition of $1 \mathrm{mM}$ PBN resulted in a significant decrease in redox potential at $24 \mathrm{~h}$ when compared to all other samples, but at the $72 \mathrm{~h}$ time point was similar to that in the $6 \% \mathrm{O}_{2}$ conditions. The addition of an exogenous source of ROS to culture media $\left(25 \mu \mathrm{M} \mathrm{H}_{2} \mathrm{O}_{2}\right)$ significantly exacerbated the progressively more positive (oxidized) redox potential seen in $20 \% \mathrm{O}_{2}$ conditions.

\subsection{Quantitation of muscle differentiation as a function of redox potential}

C2C12 differentiation was assessed by counting multinucleated myotubes immunoreactive for MHC. The kinetics of differentiation of $\mathrm{C} 2 \mathrm{C} 12$ in $20 \% \mathrm{O}_{2}$ is well known, and these cultures behaved typically with $43.9 \%( \pm 2.2 ; n=15)$ of nuclei incorporated into MHC-positive myotubes after $72 \mathrm{~h}$ (Figs. 3 and 4). At all assayed times, significantly more $\mathrm{C} 2 \mathrm{C} 12$ cells differentiated in $6 \% \mathrm{O}_{2}$ than in $20 \% \mathrm{O}_{2}$, and at $72 \mathrm{~h}, 60.0 \%( \pm 2.6 ; n=15)$ of nuclei were incorporated into myotubes in $6 \% \mathrm{O}_{2}(p<0.05$, compared to 20\%) (Figs. 3 and 4). Cultures treated with PBN also showed enhanced differentiation when compared with traditional $20 \% \mathrm{O}_{2}$ culture conditions, with significantly more myotube formation at all times analyzed $(p<0.05)$. At $24 \mathrm{~h}, 11.5 \%( \pm 3.9)$ of

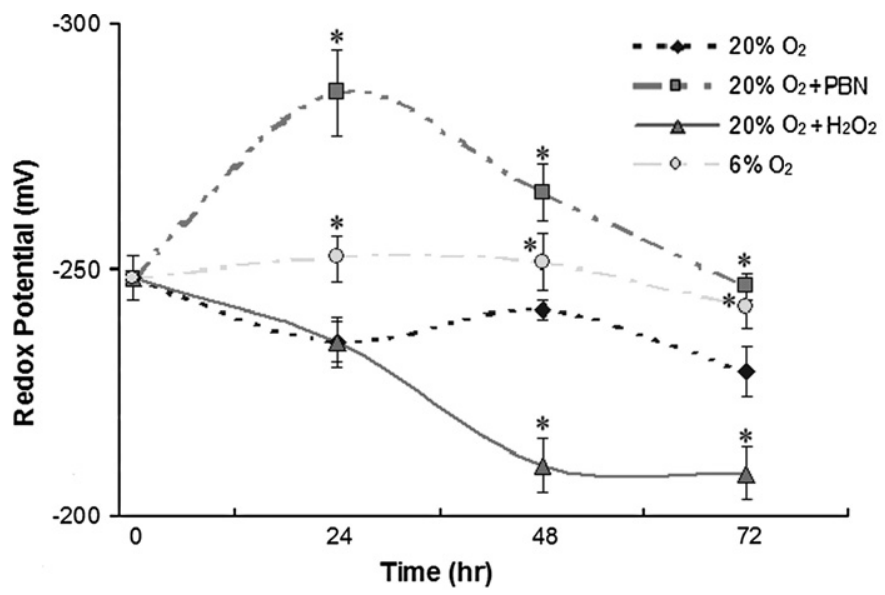

Fig. 2. Redox potential of differentiating $\mathrm{C} 2 \mathrm{C} 12$ myoblasts as a function of environmental $\mathrm{O}_{2}$ and ROS. Intracellular redox potential was calculated using the Nernst equation, with HPLC-derived concentrations of GSH and GSSH. Cultures grown in $6 \% \mathrm{O}_{2}$ (circles) maintained stable redox potentials, but those in $20 \% \mathrm{O}_{2}$ (small diamonds) gradually became more positive (oxidized) during differentiation. Treatment with the free radical trap PBN resulted in transient, significantly reduced redox potentials (squares), but $\mathrm{H}_{2} \mathrm{O}_{2}$ treatment mediated a significant sustained oxidizing redox potential (triangles) when compared to cultures in $20 \% \mathrm{O}_{2}$. Data are presented as mean millivolts $(\mathrm{mV}) \pm \mathrm{SEM}$. Asterisks $(*)$ denote statistically significant differences $(p<0.05)$ from $20 \%$ $\mathrm{O}_{2}$ conditions. 

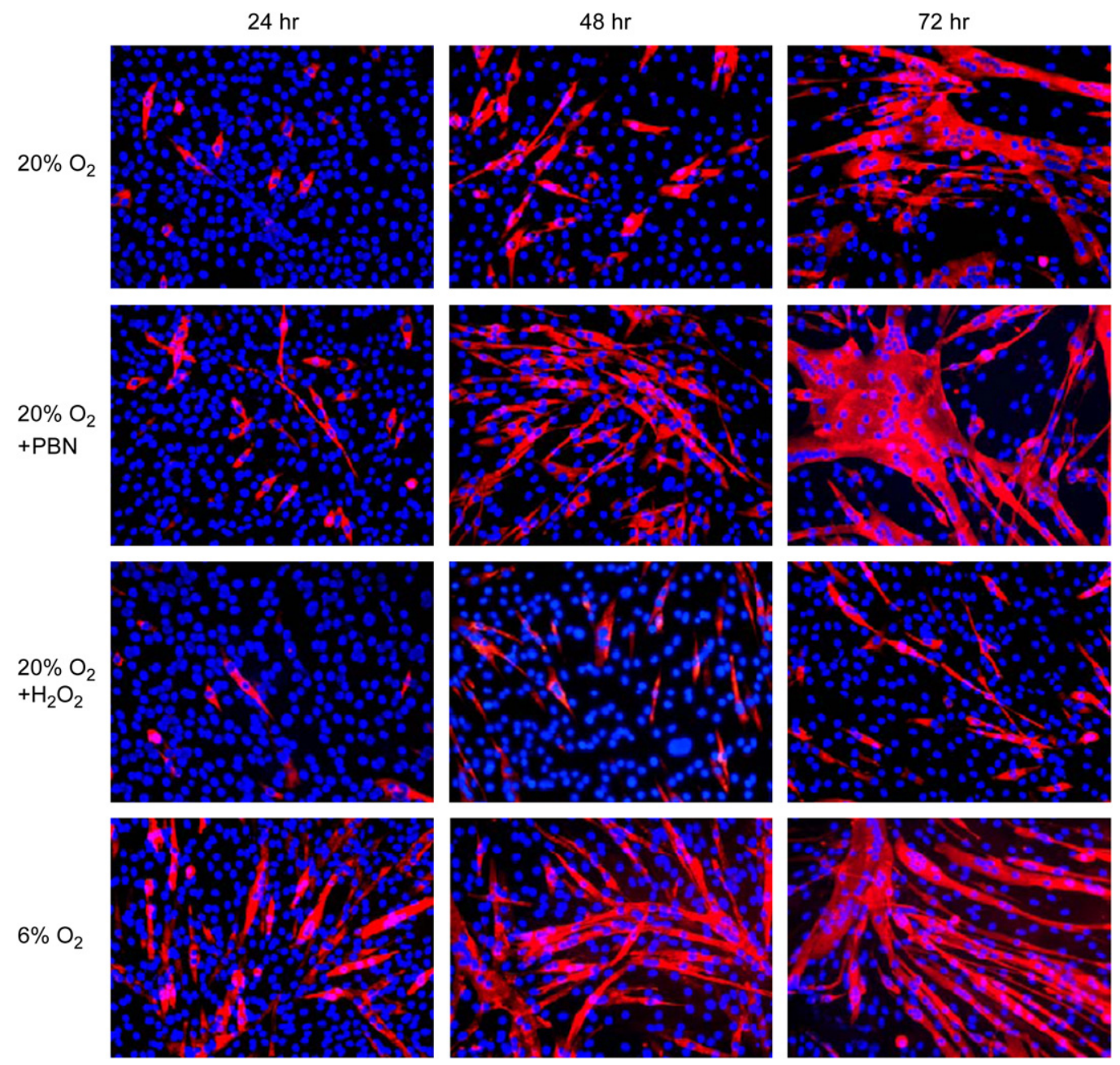

Fig. 3. Myosin heavy chain immunohistochemistry to mark differentiating myotubes as a function of redox conditions. Myosin heavy chain detection with mf20

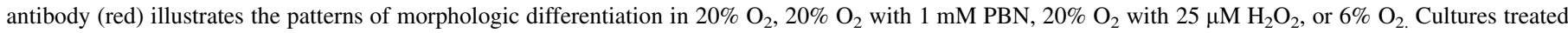
with PBN or in $6 \% \mathrm{O}_{2}$ contained more myotubes than cultures in $20 \% \mathrm{O}_{2}$, and terminal differentiation was obviously impaired in $\mathrm{H}_{2} \mathrm{O}_{2}$-treated cultures. DAPI (blue) stains nucleic acid.

PBN-treated cells were myotubes vs. $5.3 \%( \pm 1.4)$ in $20 \% \mathrm{O}_{2}$ cultures $(n=20, p<0.05)$, indicating earlier differentiation in ROS-scavenged conditions. Cultures treated with $\mathrm{H}_{2} \mathrm{O}_{2}$ showed markedly diminished differentiation, which was statistically significant at all times when compared to other culture conditions: After $72 \mathrm{~h}$, only $25.1 \%( \pm 2.7)$ of nuclei in the $\mathrm{H}_{2} \mathrm{O}_{2}$-treated cells were in differentiated myotubes $(n=15$, $p<0.05$ ) (Figs. 3 and 4).

\subsection{Myogenic bHLH gene expression as a function of redox potential}

Using real-time fluorescence quantitative PCR, expression patterns for the four myogenic bHLH transcription factors were assessed during differentiation in high vs. low oxidative stress conditions. Fold differences were determined by comparison with $\beta$-actin message abundance. $\beta$-Actin expression was unaffected by culture conditions. Cultures maintained in $6 \% \mathrm{O}_{2}$ showed a 1.9- and 1.5-fold increase in myf-5 and MRF-4 expression, compared to cells grown in $20 \% \mathrm{O}_{2}$.
Similar increases in myf-5 and MRF-4 expression were observed in cultures treated with PBN. Conversely, cultures treated with $\mathrm{H}_{2} \mathrm{O}_{2}$ showed approximately 2.7- and 3.7-fold less gene expression than cultures at $20 \% \mathrm{O}_{2}$ for myf-5 and MRF-4, respectively. In $6 \% \mathrm{O}_{2}$ and in PBN treated cultures, myogenin expression was not markedly different from that at $20 \% \mathrm{O}_{2}$, but myogenin expression was dramatically decreased by 60 -fold with $\mathrm{H}_{2} \mathrm{O}_{2}$ treatment. Expression patterns of MyoD were not affected by any treatment or culture condition. Alterations in myogenic bHLH factor gene expression are summarized in Table 1. Melting curve analysis and product electrophoresis confirmed amplification of the product of interest (not shown).

\subsection{Regulation of $p 38$ MAPK and activation of caspase-3 as a function of redox potential manipulations}

Western blotting was used to quantify the amounts of p38 MAPK and activated phosphorylated $\mathrm{p} 38$, since $\mathrm{p} 38$ promotes muscle differentiation (reviewed in Keren et al., 2006). In 


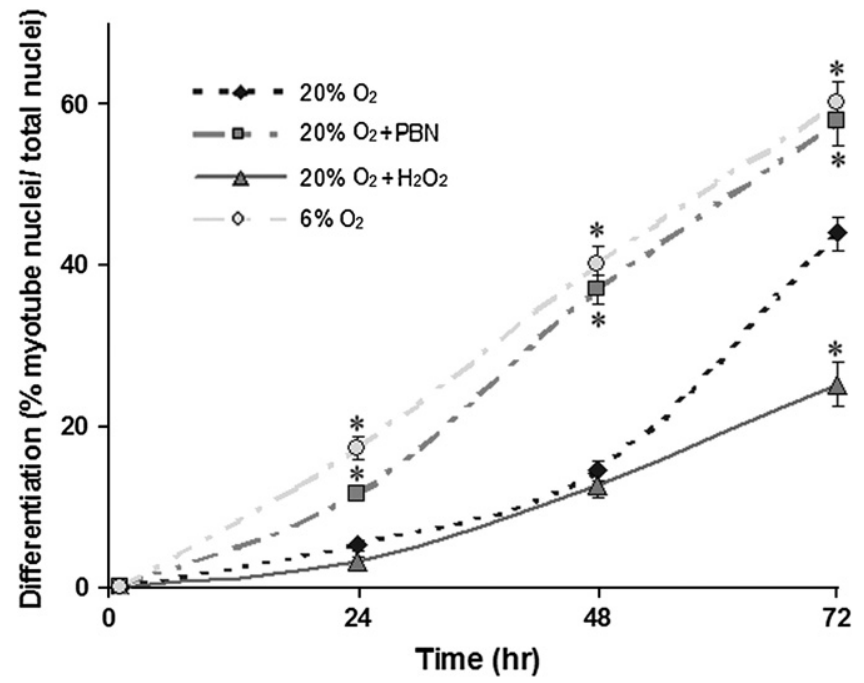

Fig. 4. Quantitative analysis of $\mathrm{C} 2 \mathrm{C} 12$ differentiation into myotubes as a function of redox conditions. Differentiated cells are defined as myotubes $(>3$ nuclei) immunoreactive to anti-myosin heavy chain antibody. Data are presented as the percentage of nuclei in differentiated cells per total nuclei $( \pm$ SEM). Asterisks $(*)$ denote statistically significant differences from $20 \%$ $\mathrm{O}_{2}$ conditions $(p<0.05)$.

addition, to determine whether cells were diverted from differentiation by apoptosis, we screened for apoptosis using western blotting with an antibody specific for the activated form of caspase-3 (Fig. 5). P38 was most abundant prior to differentiation, but only unphosphorylated p38 was detectable at that time. Differentiation in all conditions was associated with detectable phosphorylated $\mathrm{p} 38$, with no apparent differences in the absolute amount in the various conditions. At $24 \mathrm{~h}$, the percentage of phosphorylated $\mathrm{p} 38$ in the total pool appeared lowest in cells treated with $\mathrm{H}_{2} \mathrm{O}_{2}$ and those in $6 \%$ $\mathrm{O}_{2}$. At $48 \mathrm{~h}$ cells treated with $\mathrm{H}_{2} \mathrm{O}_{2}$ appeared to have the lowest percentage of phosphorylated p38. At $72 \mathrm{~h}$, no differences between the groups were apparent. We also saw no significant differences in the amount of activated caspase- 3 as a function of oxygen, $\mathrm{PBN}$, or $\mathrm{H}_{2} \mathrm{O}_{2}$.

\section{Discussion}

GSH:GSSG is increasingly recognized to be a major factor in the overall redox balance of the cell, and so was the focus of

Table 1

Myogenic gene expression in differentiating $\mathrm{C} 2 \mathrm{C} 12$ cells as a function of redox conditions

\begin{tabular}{llll}
\hline Gene & \multicolumn{3}{l}{ Treatment/Condition } \\
\cline { 2 - 4 } & $6 \% \mathrm{O}_{2}$ & $20 \% \mathrm{O}_{2}+1 \mathrm{mM}$ & $20 \% \mathrm{O}_{2}+25 \mu \mathrm{M}$ \\
& & $\mathrm{PBN}$ & $\mathrm{H}_{2} \mathrm{O}_{2}$ \\
\hline Myf-5 & $+1.9 \pm 0.6^{*}$ & $+2.2 \pm 0.8^{*}$ & $-2.7 \pm 1.7^{*}$ \\
MyoD & $+0.3 \pm 0.6$ & $-0.2 \pm 0.4$ & $+0.2 \pm 0.3$ \\
Myogenin & $-0.2 \pm 0.5$ & $+2.1 \pm 1.2$ & $-60.1 \pm 12.4^{*}$ \\
MRF-4 & $+1.5 \pm 0.4^{*}$ & $+1.9 \pm 0.5^{*}$ & $-3.7 \pm 0.8^{*}$ \\
\hline
\end{tabular}

Quantitative real-time PCR was performed on RNA collected after $72 \mathrm{~h}$ of differentiation. Data are expressed as fold-difference relative to results from cells maintained in $20 \% \mathrm{O}_{2}$. Asterisks $(*)$ denote a statistically significant $(p<0.05)$ expression difference, compared to $20 \% \mathrm{O}_{2}$ conditions.

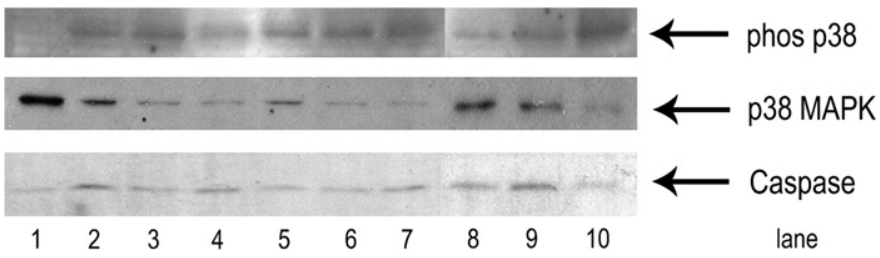

Fig. 5. Western blotting to determine abundance of total p38 MAPK and its phosphorylated form, and activated caspase-3. Lane 1: Before differentiation. Lanes 2-4: $\mathrm{C} 2 \mathrm{C} 12$ cells differentiated in $6 \% \mathrm{O}_{2}$ at days 1,2 , and 3 of differentiation. Lanes 5-7: $20 \% \mathrm{O}_{2}$ at days 1,2, and 3 of differentiation. Lanes 8-10: $20 \% \mathrm{O}_{2}+\mathrm{H}_{2} \mathrm{O}_{2}$ at days 1, 2, and 3 of differentiation. Phosphorylated p38 was not detectable before differentiation, but differentiation resulted in increased phosphorylated p38 in all conditions. Over the three day time course, $\mathrm{H}_{2} \mathrm{O}_{2}$ treated cells appeared to have the lowest ratio of phosphorylated p38 to total, but the absolute differences between conditions were small. All bands were imaged at their expected molecular weights: p38 at $38 \mathrm{kDa}$, phosphorylated p38 at $40 \mathrm{kDa}$, activated caspase-3 at $19 \mathrm{kDa}$.

this investigation of myoblasts undergoing differentiation. Cysteine is a precursor for GSH, the limiting amino acid in GSH synthesis. Progression through terminal differentiation (with loss of mitotic capacity) has been associated with depletion of GSH and an increase in GSSG (Balin and Allen, 1989), implying that differentiating cells usually increase redox potential (become more oxidative) during the transition from a proliferative state to a differentiated phenotype. For example, vascular smooth muscle differentiation is promoted by a variety of treatments that increase the oxidative state of cells through p38 MAPK-dependent pathways (Su et al., 2001).

The reported general cellular bias to execute differentiation as a function of increased oxidative conditions is not supported by data presented here for differentiating $\mathrm{C} 2 \mathrm{C} 12$ myoblasts. To the contrary, maintenance of a low redox potential and a reducing redox environment correlated with an increase in $\mathrm{C} 2 \mathrm{C} 12$ muscle differentiation. Perturbations that resulted in more positive redox potentials (more oxidative) of $\mathrm{C} 2 \mathrm{C} 12$ cells significantly slowed their differentiation, and these morphologic observations were supported by changes in expression of the myogenic bHLH transcription factors.

Thus, these data suggest that the pattern of redox potential changes during differentiation is dependent on the particular lineage undergoing differentiation, and that redox-regulated genes may be one factor in determining lineage selection. For example, the data here and related work in primary myoblasts and mesenchymal stem cell lines (Csete et al., 2001; Lee et al., 2006) show that muscle differentiation is promoted by a reducing redox environment. In contrast, an oxidized redox environment promotes adipogenic differentiation (Takahashi and Zeydel, 1982; Csete et al., 2001). Furthermore, the shifts in glutathione (GSH) and glutathione disulfide (GSSG) as a function of adipogenic differentiation are opposite those shown here for muscle differentiation (Takahashi and Zeydel, 1982). Thus, it may be possible to manipulate the redox conditions of pluripotent cells to promote one of these fates over another. In the clinical setting, the oxidized muscle environment of aging is associated with increased adipogenic potential of myoblasts (Taylor-Jones et al., 2002). 
Expression of myogenic bHLH genes appears to be regulated in part by redox conditions. In our experiments, myf5 expression was considerably lower in oxidative conditions, but MyoD expression was unchanged, suggesting that early muscle differentiation events may not be as redox-sensitive as later regenerative events. Myogenin expression was most sensitive to redox conditions in our studies. In other studies, silencing of myogenin has been associated with defective terminal muscle differentiation (Dedieu et al., 2002) similar to that seen in our $\mathrm{H}_{2} \mathrm{O}_{2}$-treated $\mathrm{C} 2 \mathrm{C} 12$ cells. In both cases, 'early' bHLH genes (myf5 and MyoD) were unable to functionally compensate for loss of myogenin expression at higher redox potentials. We did not see significant changes in p38 signaling as a function of redox conditions, which is somewhat inconsistent with the known role of $\mathrm{p} 38$ in promoting muscle differentiation (Keren et al., 2006). However, the first time point assessed was at $24 \mathrm{~h}$ into differentiation and the peak signaling may have been missed. In addition, p38 promotes muscle differentiation in part by interacting early in differentiation with the myogenic bHLH genes, particularly Myf5, and again the peak activity may have been missed in our assay. Finally, the particular quantities and types of oxidants in a cell are variables that are not addressed in most studies.

Though this study focuses on differentiation, other basic aspects of muscle stem cell biology are altered by oxygen and redox shifts in the culture environment. Proliferation of primary rodent myoblasts (Chakravarthy et al., 2001) and murine satellite cells (Csete et al., 2001) is increased in $6 \% \mathrm{O}_{2}$ vs. $20 \% \mathrm{O}_{2}$. However, we found that proliferation of $\mathrm{C} 2 \mathrm{C} 12$ cells is the same in both these conditions (not shown), likely due to their transformed state. Cultured myoblasts from antioxidant deleted mice have a lower threshold for apoptosis in culture compared to wild type myoblasts (Lee et al., 2006), but apoptosis was not significantly affected by the redox manipulations in $\mathrm{C} 2 \mathrm{C} 12$ cells, which again may be due to their transformed state.

In summary, these data emphasize that manipulations of the oxygen microenvironment or the intracellular redox potential can have profound effects on muscle differentiation. In order to further characterize the role of redox regulation in muscle differentiation, global measures of redox potential must be accompanied by more precise measures of the quantity and quality of intracellular oxidants. These measurements are the focus of ongoing work.

\section{Acknowledgments}

This research was supported by the Institute of Gerontology, University of Michigan, Contract grant T32 AG0011417 (J.M.H.), and the National Institute on Aging, Contract grant PO1 AG20591 (M.C.) and the Emory Anesthesiology Department.

\section{References}

Balin AK, Allen RG. Molecular bases of biologic aging. Clin Geriatr Med 1989;5(1):1-21.
Beauchamp JR, Heslop L, Yu DS, Tajbakhsh S, Kelly RG, Wernig A, et al. Expression of CD34 and Myf5 defines the majority of quiescent adult skeletal muscle satellite cells. J Cell Biol 2000;151(6):1221-34.

Berkes CA, Tapscott SJ. MyoD and the transcriptional role of myogenesis. Semin Cell Biol 2005;16(4-5):585-95.

Bradford MM. A rapid and sensitive method for the quantitation of microgram quantities of protein utilizing the principle of protein-dye binding. Anal Biochemy 1976;72:248-54.

Chakravarthy MV, Spangenburg EE, Booth FW. Culture in low levels of oxygen enhances in vitro proliferation potential of satellite cells from old skeletal muscles. Cell Mol Life Sci 2001;58(8):1150-8.

Cornelison DDW, Wold BJ. Single-cell analysis of regulatory gene expression in quiescent and activated mouse skeletal muscle satellite cells. Dev Biol 1997;191(2):270-83.

Cotgreave IA, Gerdes RG. Recent trends in glutathione biochemistry-glutathione-protein interactions: a molecular link between oxidative stress and cell proliferation? BiochemBiophys Res Commun 1998;242(1):1-9.

Csete M, Walikonis J, Slawny N, Wei Y, Korsnes S, Doyle JC, et al. Oxygenmediated regulation of skeletal muscle satellite cell proliferation and adipogenesis in culture. J Cell Physiol 2001;189(2):189-96.

Dedieu S, Mazeres G, Cottin P, Brustis JJ. Involvement of myogenic regulator factors during fusion in the cell line C2C12. Int JDev Biol 2002;46(2): 235-41.

Faulkner JA, Brooks SV, Zerba E. Muscle atrophy and weakness with aging: contraction-induced injury as an underlying mechanism. J Gerontol 1995;A50: 124-9.

Hamilton ML, Van Remmen H, Drake JA, Yang H, Guo ZM, Kewitt K, et al. Does oxidative damage to DNA increase with age? Proc Natl Acad Sci 2001;98(18):10469-74.

Harris C. Glutathione biosynthesis in the postimplantation rat conceptus in vitro. Toxicol Appl Pharmacol 1993;120(2):247-56.

Hazelton GA, Lang CA. Glutathione peroxidase and reductase activities in the aging mouse. Mech Ageing Dev 1985;29(1):71-81.

Jones DP, Mody Jr VC, Carlson JL, Lynn MJ, Sternberg Jr P. Redox analysis of human plasma allows separation of pro-oxidant events of aging from decline in antioxidant defenses. Free Radic Biol Med 2002;33(9): 1290-300.

Keren A, Tamir Y, Bengal E. The p38 MAPK signaling pathway: a major regulator of skeletal muscle development. Mol Cell Endocrinol 2006;252 $(1-2): 224-30$.

Kim SS, Rhee S, Lee KH, Kim JH, Kim HS, Kang MS, et al. Inhibitors of the proteasome block the myogenic differentiation of rat L6 myoblasts. FEBS Lett 1998;433(1-2):47-50.

Kirlin WG, Cai J, Thompson SA, Diaz D, Kavanagh TJ, Jones DP. Glutathione redox potential in response to differentiation and enzyme inducers. Free Radic Biol Med 1999;27(11-12):1208-18.

LeBel CP, Ischiropoulos H, Bondy SC. Evaluation of the probe $2^{\prime}, 7^{\prime}$-dichlorofluorescein as an indicator of reactive oxygen species formation and oxidative stress. Chem Res Toxicol 1992;5(2):227-31.

Lee S, Shin HS, Shireman PK, Vasilaki A, Van Remmen H, Csete M. Glutathione-peroxidase-1 null muscle progenitor cells are globally defective. Free Radic Biol Med 2006;41(7):1174-84.

Mecocci P, Fano G, Fulle S, MacGarvey U, Shinobu L, Polidori MC, et al Age-dependent increases in oxidative damage to DNA, lipids and proteins in human skeletal muscle. Free Radic Biol Med 1999;26(3-4):303-8.

Newton GL, Fahey RC. Determination of biothiols by bromobimane labeling and high-performance liquid chromatography. Methods Enzymol 1985;251: $148-66$.

Noy N, Schwartz H, Gafni A. Age-related changes in the redox status of rat muscle cells and their role in enzyme-aging. Mech Ageing Dev 1985;29(1): 63-9.

Pansarasa O, Castagna L, Colombi B, Vecchiet J, Felzani G, Marzatico F. Age and sex differences in human skeletal muscle: role of reactive oxygen species. Free Radic Res 2000;33(3):287-93.

Pfau JC, Schneider JC, Archer AJ, Sentissi J, Leyva FJ, Cramton J. Environmental oxygen tension affects phenotype in cultured bone marrow-derived macrophages. Am J Physiol Lung Cell Mol Physiol 2004;286(2): L354-62. 
Pineda-Molina E, Klatt P, Vazquez J, Marina A, Garcia de Lacoba M, PerezSala D, et al. Glutathionylation of the p5-subunit of NF- $\kappa B$ : a Mechanism for redox-induced inhibition of DNA binding. Biochemistry 2001;40(47): 14134-42.

Reynaert NL, van der Vliet A, Guala AS, McGovern T, Hristova M, Pantano C, et al. Dynamic redox control of NK-kappaB through glutaredoxin-regulated S-glutathionylation of inhibitory kappB kinase beta Proc Natl Acad Sci USA 2006;103(35):13086-91.

Rudnicki MA, Braun T, Hinuma S, Jaenisch R. Inactivation of MyoD in mice leads to up-regulation of the myogenic HLH gene Myf-5 and results in apparently normal muscle development. Cell 1992;71(3):383-90.

Schafer FQ, Buettner GR. Redox environment of the cell as viewed through the redox state of the glutathione disulfide/glutathione couple. Free Radic Biol Med 2001;30(1):1191-212.

Sen CK, Packer L. Antioxidant and redox regulation of gene transcription. FASEB J 1996;10(7):709-20.
Su B, Mitra S, Gregg H, Flavahan S, Chotani MA, Clark KR, et al. Redox regulation of vascular smooth muscle cell differentiation. Circ Res 2001; 89(1):39-46.

Takahashi S, Zeydel M. Gamma-glutamyl transpeptidase and glutathione in aging IMR-90 fibroblasts and in differentiating 3T3 L1 preadipocytes. Arch Biochem Biophys 1982;214(1):260-7.

Taylor-Jones JM, McGehee RE, Rando TA, Lecka-Czernik B, Lipschitz DA, Peterson CA. Activation of an adipogenic program in adult myoblasts with age. Mech Ageing Dev 2002;123(6):649-61.

Wang H, Joseph JA. Quantifying cellular oxidative stress by dichlorofluorescein assay using microplate reader. Free Rad Biol Med 1999;27(5-6):612-6.

Yaffe D, Saxel O. A myogenic cell line with altered serum requirements for differentiation. Differentiation 1977;7(3):159-66.

Yun K, Wold B. Skeletal muscle determination and differentiation: story of a core regulatory network and its context. Curr Opin Cell Biol 1996;8(6): 877-89. 